\title{
A Hidra do Iguaçu
}

\section{Cristiana Miranda'}

Resumo: Uma experiência cinematográfica que mergulha nas águas da memória colonial e lança um olhar crítico aos padrões impostos pelo uso comercial das máquinas cinematográficas. O uso da técnica analógica de filmar aposta nas possibilidades transformadoras do material fílmico experimentado de forma livre. Um percurso por lugares de memória não espetaculares da história da colonização.

Palavras-chaves: Cinema experimental. Cinema líquido. Memória. Estudos decoloniais.

\section{The Iguaçu Hydra}

Abstract: A cinematic experience that plunges into colonial memory and takes a critical look at the standards imposed by the commercial use of cinematographic machines. The use of the analogue technique of filming bet on the new possibilities of the film material when experienced with freedom. A journey through not spectacular places of memory in the history of colonization.

Keywords: Experimental cinema. Liquid cinema. Memory. Decolonial history.

I Doutora em artes visuais no Programa de Pós-graduação em Artes da Universidade do Estado do Rio de Janeiro (UERJ). Mestre em Comunicação Social no Programa de Pós-graduação em comunicação da Universidade Federal do Rio de Janeiro (UFRJ). Graduada em Sociologia e Política na PUC/RJ. Professora na Universidade Hélio Alonso, Muniz Barreto, 51 - Botafogo, Rio de Janeiro - RJ, 22251-090.E-mail: cristianamiranda.cris@gmail.com. ORCID: https:// orcid.org/0000-0001-9385-458X. Lattes iD: http://lattes.cnpq.br/5588981825074538. Rio de Janeiro, Brasil. 
Estamos condenados a viver juntos nesse planeta azul. Sob um mesmo céu compartilhamos o mundo entre muitos viventes. É na relação que mantemos com o múltiplo e diverso conjunto dos seres com quem coabitamos esse planeta que se manifesta o que somos enquanto humanidade. A arte faz parte desse trabalho permanente de reparação das relações entre os humanos e tudo o que vive.

Somos seres de história porque temos desejos de vida. A matéria que nos dá corpo faz parte de uma natureza que é força em si, e com a qual estamos em sintonia sempre que manifestamos a vida. As matérias da arte ganham o corpo do artista. O cinema é uma experiência de imersão feita de carne e máquinas que reconfigura o fluxo do tempo e nos reconecta com a memória. Apresentar uma expressão sensível da memória é um dos seus maiores fascínios.

Tributo à modernidade, o cinema está também conectado com práticas muito antigas de criação. As máquinas de filmar trazem engrenagens rolantes e matérias orgânicas que mergulham em líquidos reveladores, atualizando arcaicas ferramentas de manipulação. $O$ trabalho que aqui apresento traz uma proposta de cinema que pesquisa a técnica analógica de filmar e a utiliza como instrumento de investigação da história.

Nossos corpos carregam memórias e lembranças. Trazemos em nós mesmos e somos partes de complexos fluxos temporais. É no plural que experimentamos o tempo. Durações diferenciadas e simultaneidades são estratégias cinematográficas de montagem que também operam em nossa relação com o tempo. Os filmes, assim como as lembranças, fazem parte de um esforço em decifrar e exprimir o acontecimento vivido.

Nos três filmes que compõem a série "Na risada salgada das rochas"1 mergulho nas águas noturnas da memória e nos líquidos do cinema, assumo riscos, tateio invisibilidades e percorro o escuro. Como artista, proclamo a potência de encantamento do mundo que é o cinema. Vivemos num tempo desencantado onde é urgente a construção de novas bases para a experiência do comum. Nosso desafio é experimentar formas de estarmos

1 A série "Na risada salgada das rochas" é composta pelos filmes: "Sobre aquilo que nos diz respeito", "Tantas vozes no silêncio do agora" e "A Hidra do Iguaçu". Os filmes fazem parte da tese de doutorado "Peixes de prata: sais, líquidos e cinema" defendida em 2019 no Programa de Pós Graduação em Artes PPGARTES/UERJ, com orientação do professor doutor Luiz Cláudio da Costa. 
juntos onde haja desejo de vida e não medo dominando nossos afetos. O cinema experimental é um exercício crítico de pensamento e investigação que nos põe em estado de alerta. Proponho um cinema que nos inunde com práticas líquidas, que nos transporte em enxurrada para um estado desperto de consciência, onde sejamos capazes de ouvir as vozes que povoam nossos silêncios e perceber aquilo que nos diz respeito.

\section{Na risada salgada das rochas}

Meu cinema de aparições líquidas é também um cinema de memória. A necessidade de salientar a presença do passado no momento atual, sempre foi um impulso de criação em minha prática cinematográfica. A lembrança é uma aparição que nunca deixa de enfrentar as forças do esquecimento. No mundo em que vivemos permanecemos separados do conhecimento de nosso passado, condenados a um presente sem memória, que precisa da produção em massa das imagens da indústria cultural para a manutenção de uma política de medo e servidão. Em meu cinema, pesquisar a memória é buscar por enunciados que consigam desarranjar essa máquina despótica que serve à logica do esquecimento.

Sou carioca filha de mãe catarinense e pai mineiro. Durante a infância, eu viajava todos os verões com minha família, na variante cor manteiga de meu pai, pelas estradas que unem o Rio de Janeiro ao sul do Brasil. Com minha avó materna aprendi, em noites de chuva a beira mar, as artes do bordado. Lembro-me que para avaliar se eu estava fazendo corretamente o desenho das linhas coloridas no pano, minha avó me pedia para olhar o avesso do bordado. As artes do bordado não ficaram como uma prática em minha vida, mas essa atenção pelo avesso da imagem permanece ainda hoje na pesquisa que move o cinema que realizo. As linhas cruzadas por trás das imagens celebradas de nossa história são o que me interessa investigar e pôr em ação em meus filmes.

"A Hidra do Iguaçu" foi todo filmado em Angola, entre os meses de agosto de 2018 e janeiro de 2019, período de minha bolsa sanduíche no programa CAPES. Com uma câmera $16 \mathrm{~mm}$, filmes coloridos e P\&B, um tanque e químicas para revelação viajei por Angola, de Luanda ao sul do país, em busca de lugares de memória apagados de nossa história colonial. Cidades pouco conhecidas como Lubango, Massangano, Benguela e Chibia, foram locações onde apontei minha câmera em busca de uma história que nunca me foi contada, mas que ecoava em minhas investigações. 
Aprendi na umbanda que tudo é sagrado, os restos, as pedras, as folhas, as histórias. Para lidar com o sagrado da vida, realizo um cinema que atualiza um um saber sobre a câmera $16 \mathrm{~mm}$, o preparo do filme, a fotometragem da luz, o processamento da imagem. O cinema é em si mesmo uma prática de encantamento da vida. O que surge no pequeno retângulo do filme é resultado de uma prática ritualizada de ressignificação do cotidiano. Em meu cinema, realizo práticas de re-encantamento que dialogam com o imprevisível e voltam sua atenção para as fendas temporais da realidade, para os traços anacrônicos das ruas por onde caminhamos.

Filmar com câmeras $16 \mathrm{~mm}$ em plena segunda década do século XXI não é uma escolha inconsequente. Para defende-la gostaria de evocar um conceito proposto pelo cineasta John Akomfrah, ainda que num primeiro momento ele pareça referir-se a um projeto cinematográfico incompatível com o uso do filme. Trata-se da ideia de "digitopia"2. A tecnologia digital chega ao mundo da imagem na década de 80 do século passado, no Brasil ela se torna majoritariamente usada pelos profissionais apenas na virada do século. Ainda que o advento do digital seja algo bastante recente, já na primeira década do século XXI a indústria cinematográfica viu o desmonte de seu parque tecnológico analógico e sua substituição por novas máquinas de tecnologias digitais.

O novo estatuto da imagem surgido com a tecnologia digital implicou não apenas em um novo parque tecnológico, ele fez surgir também um parque abandonado, cujo maquinário se tornou obsoleto. As antigas máquinas analógicas, descartadas pela tecnologia digital, tornaram-se disponíveis para um outro uso. Filmar em $16 \mathrm{~mm}$ hoje é uma aposta nas possibilidades transformadoras que surgem quando as potências criativas do material fílmico são experimentadas de forma livre. Proponho usar a câmera $16 \mathrm{~mm}$ e processar manualmente a imagem sem as amarras dos padrões fotoquímicos da indústria do entretenimento.

Nesse sentido a "digitopia", enquanto esperança no surgimento de um novo e libertário cinema a partir das transformações trazidas pela tecnologia digital, inclui também a libertação das antigas máquinas analógicas. Lançadas aos porões do desuso comercial, elas têm seu emprego recriado por artistas que pretendem experimentar as possibilidades poéticas resul-

2 Akomfrah, John. Digitopia e os espectros da diáspora. Journal of Media Practice. Universidade de Exeter, In: O cinema de John Akomfrah, Centro Cultural Banco do Brasil, Rio de Janeiro: 2018. 
tantes da maneira como a imagem surge na tecnologia analógica. Artistas que reconhecem na película e nas câmeras fílmicas um processo de criação de imagens repleto de surpresas e possibilidades poéticas, onde os mecanismos do filme e do processamento da imagem estabelecem uma experiência perceptiva de imersão, suspensão e êxtase.

O digital liberou o analógico para uma nova sua forma de absorver os erros e acidentes que lhe são próprios. No livro "Pure War", Paul Virilio propõe a ideia de um "acidente original" que acompanha cada técnica desde o seu início. Para além da análise dos produtos da tecnologia, o autor afirma ser importante também pensar os acidentes que cada uma delas provoca. Cada vez que se cria um aparato técnico e se estabelece sua operação, produz-se um defeito específico ${ }^{3}$.

Interessam-me os defeitos específicos que o filme, girando na roda dentada da câmera e na espiral plástica do tanque de revelação, pode provocar na imagem. Interessa-me esse regime de visualidade criado por um aparato técnico cujo princípio normativo eu posso questionar e transformar em função de uma experimentação estética e sensorial, sem a cobrança de um resultado visual específico a ser obtido. Usar filmes vencidos, alterar o processamento e a velocidade da câmera são formas de provocar esse questionamento epistemológico da técnica que o uso experimental possibilita. Desrespeitar os padrões da indústria cultural através dos acidentes da imagem fotoquímica é um dos motivos "digitópicos" pelos quais eu filmo com equipamento analógico e revelo manualmente a imagem.

Em seus escritos sobre o cinema, Antonin Artaud afirma apreciar a virtude própria que o cinema possui em expressar o movimento e a matéria secreta das imagens ${ }^{4}$. Artaud reconhece o imprevisto e o misterioso que está sempre presente no filme, e essa embriaguez que a materialidade do cinema, na rotação permanente do filme pelas engrenagens dentadas da câmera, comunica diretamente ao cérebro. $O$ cinema é capaz de sacudir o espírito, independente de qualquer representação. Essa atmosfera de transe que Artaud percebe como intrínseca à experiência cinematográfica está intimamente associada as práticas e revelações de meu cinema.

3 Virilio, Paul e Lotringer, Sylvère. Pure War. New York: Semiotext(e). 1997. "Every technology, every science should choose its specific accident, and reveal it as a product, not in a moralistic, protectionist way (safety first), but rather as a product to be 'epistemo-technically' questioned." Página 39.

4 Os escritos de Antonin Artaud sobre o cinema datam dos anos vinte e foram publicados em espanhol no livro: Artaud, Antonin. El cine. Alianza Editorial. Madrid: 1982. 
Nos anos que acompanharam a realização dos filmes que fazem parte da série "Na risada salgada das rochas", a cidade do Rio de Janeiro foi atravessada por transformações que envolveram sua participação em grandes eventos internacionais. Para adaptar-se às exigências dos padrões de qualidade de serviços, transporte e segurança voltados para o turismo dos grandes eventos, a cidade foi submetida a uma série de obras. Nesse processo surgiram descobertas arqueológicas que ressuscitaram histórias aparentemente enterradas. Um porto construído no início do século XIX, o Cais do Valongo, foi desencavado praticamente intacto na rua Barão de Tefé, ao lado do Hospital Servidores do Estado, entre dois marcos histórico-geográficos do Rio de Janeiro: o Morro da Conceição e o Morro da Livramento.

As obras impostas à cidade literalmente esbarraram com uma infinidade de pedras e ossos que ressurgiram de um passado aparentemente esquecido. A descoberta do Cais do Valongo foi um acontecimento pouco falado, mesmo a patrimonialização da área pela Unesco não proporcionou amplos e profundos debates. Talvez pela gigantesca violência daquilo que esse desvendamento trouxe à narrativa histórica da cidade. O desenterrar dessas pedras nos fez conhecer a nós mesmos como o maior porto negreiro das Américas, por onde desembarcaram mais de 4 milhões de africanos escravizados ao longo de séculos. Lugar de diáspora, de percursos transatlânticos, o Rio é uma cidade de complexas encruzilhadas.

A série começa nas ruínas recuperadas e nos escombros acumulados da área portuária do Rio de Janeiro e segue um longo percurso espacial e temporal que atravessa o oceano Atlântico. Os filmes redesenham o triângulo colonial em novos traçados e percorrem lugares de memória que não fazem parte dos espaços espetaculares da história da colonização.

Começamos com "Sobre aquilo que nos diz respeito" no Jardim Suspenso do Valongo, o monumento do patriarcado republicano racista, que pretendeu tornar mais higienizada e civilizada sua nova capital. Seguimos com "Tantas vozes no silêncio do agora" pelos porões dos casarões imperiais do segundo reinado e, por fim, desembarcamos em Luanda, diante da pequena igreja do Século XVI, onde eram batizados e registrados os prisioneiros, antes de embarcarem para a travessia da "kalunga grande"5 em direção ao Brasil.

5 "Kalunga grande" é o termo como era chamado o oceano pelos povos Mbundu, do antigo Reino do Ndongo, localizado no norte de Angola. 
Nesses filmes volto-me para o passado não em busca de uma origem, mas em busca de uma historicidade sem trégua, inacabada e sempre aberta. Proponho escovar a história a contrapelo, em busca dos fragmentos escondidos nos fazeres cotidianos que o penteado oficial da história esconde. Nas "Teses sobre a história" (Benjamin, 1940) o passado é compreendido como um relâmpago, uma imagem que fulgura para logo deixar de ser vista. Como fixar esse relâmpago infinito e instantâneo? Como criar uma imagem do passado que seja capaz de atuar como uma força de transformação no presente?

A imagem do passado só pode surgir no presente no instante de sua recognoscibilidade. A ideia benjaminiana de recognoscibilidade compreende a memória como uma construção ativa. Não se trata de reconhecer o passado como ele realmente foi, trata-se de reconhecer o passado na permanente ameaça de esquecimento imposta pelo presente. As grandes narrativas nos falam de um lugar que não nos pertence, um país que nunca foi nosso e onde não nos reconhecemos. No livro "Flecha no tempo" Luiz Antonio Simas e Luiz Rufino falam sobre um apagão histórico ao qual estamos submetidos, um estado de "carrego colonial" onde as memórias estão esvaziadas e nossa compreensão sobre nós mesmos confundida (Rufino e Simas, 2018). O cinema é uma arma na trincheira desse descarrego que nos é urgente.

Pesquisar a história é também pesquisar a linguagem das outras experiências que nos constituem, exercitar a crítica do pensamento colonial ao qual estamos submetidos e investigar outras gramáticas históricas, que não entram no cânone racista/positivista/patriarcal do Brasil atual. John Akomfrak lista algumas "tiranias conceituais" em oposição as quais o Black Áudio Film Collective definiu suas escolhas e criações. Dentro da obsessão pela "imagem de si" presente nos debates do cinema negro, existiu a constatação de que a construção de uma imagem adequada, uma imagem de verdade e intimidade, envolve necessariamente uma declaração de guerra à imagem-máquina do cinema comercial, pois seus padrões industriais são hostis a própria possibilidade de um cinema digitópico negro (Akomfrah, 2007).

Para o cinema experimental que realizo, os padrões industriais do cinema também são hostis. A imagem-máquina do $4 k$, imposta como padrão de exibição nas salas comerciais, não tolera o caráter imprevisível das imagens que nascem nos banhos do processamento fotoquímico manual, não experimenta o contínuo rolar pela roda dentada posta em movimento pelo mecanismo de corda da câmera $16 \mathrm{~mm}$. A aposta na permanência da película e do maquinário analógico como ferramenta criativa para o cinema é uma trincheira, uma prática de resistência e re-encantamento. 
Os filmes da série "Na risada salgada das rochas" podem ser vistos nos links:

A Hidra do Iguaçu: https://vimeo.com/384890780

Tantas vozes no silêncio do agora: https://vimeo.com/289126459

Sobre aquilo que nos diz respeito: https://vimeo.com/217573299

\section{O espelho d'água}

As águas sempre encontram seus caminhos. Fluindo em contínuo movimento, dentro, sob ou acima de nós, elas estão em permanente circulação. Mas as águas também sabem ficar imóveis. Quando paradas elas formam um espelho cuja imagem nos devolve o nosso olhar, invertido e cristalino. Quanto mais escuro for o local onde se formou o espelho d'água, tanto mais nítida será a visão da imagem refletida. Na superfície imóvel do líquido, a imagem que vemos no espelho d'água nunca para de nos olhar.

Cheguei em Luanda no final do "cacimbo", época fresca e muito nevoada que é o mês de agosto. "Cacimbo" é uma palavra Kimbundo, uma das línguas Bantu faladas no norte de Angola. "Cacimbo" significa névoa, assim é chamado o inverno em Angola. A cidade retumbou em meus sentidos como se soasse um "cinguvo", o grande tambor usado pelos povos Nyaneka-Humbe ${ }^{6}$ para a comunicação entre as aldeias. O "cinguvo" emite um som parecido com o uivo do hipopótamo. É um tambor enorme feito de madeira e couro, com uma forma trapezoidal. A chegada em Luanda fez ferver os meus sentidos. As feras pareciam correr livres dentro de mim.

Em Luanda é possível perceber de forma absolutamente imediata aquilo que Jacques Lacan identifica como a preexistência de um olhar, "eu só vejo de um ponto, mas em minha existência sou olhado de toda parte" (Lacan, 1964). Tudo nos olha em Angola, os rostos, as paisagens, o vento, as águas, o sol e a noite. Em Luanda também a terra vermelha, sobre a qual a cidade está erguida, nos olha, e nos interroga, com a violência da poeira grossa que endurece nossos cabelos e faz arder nossos olhos. A experiência incontornável desse ver ao qual estou submetida de modo original foi um dos marcos de minha chegada em Luanda.

6 Nyaneka-Humbe é o grupo étnico linguístico das nações tradicionais que habitam a província da Huíla, no sul de Angola. 
Figura 1

Cristiana Miranda

A Hidra do Iguaçu, 202.

Fotograma do filme

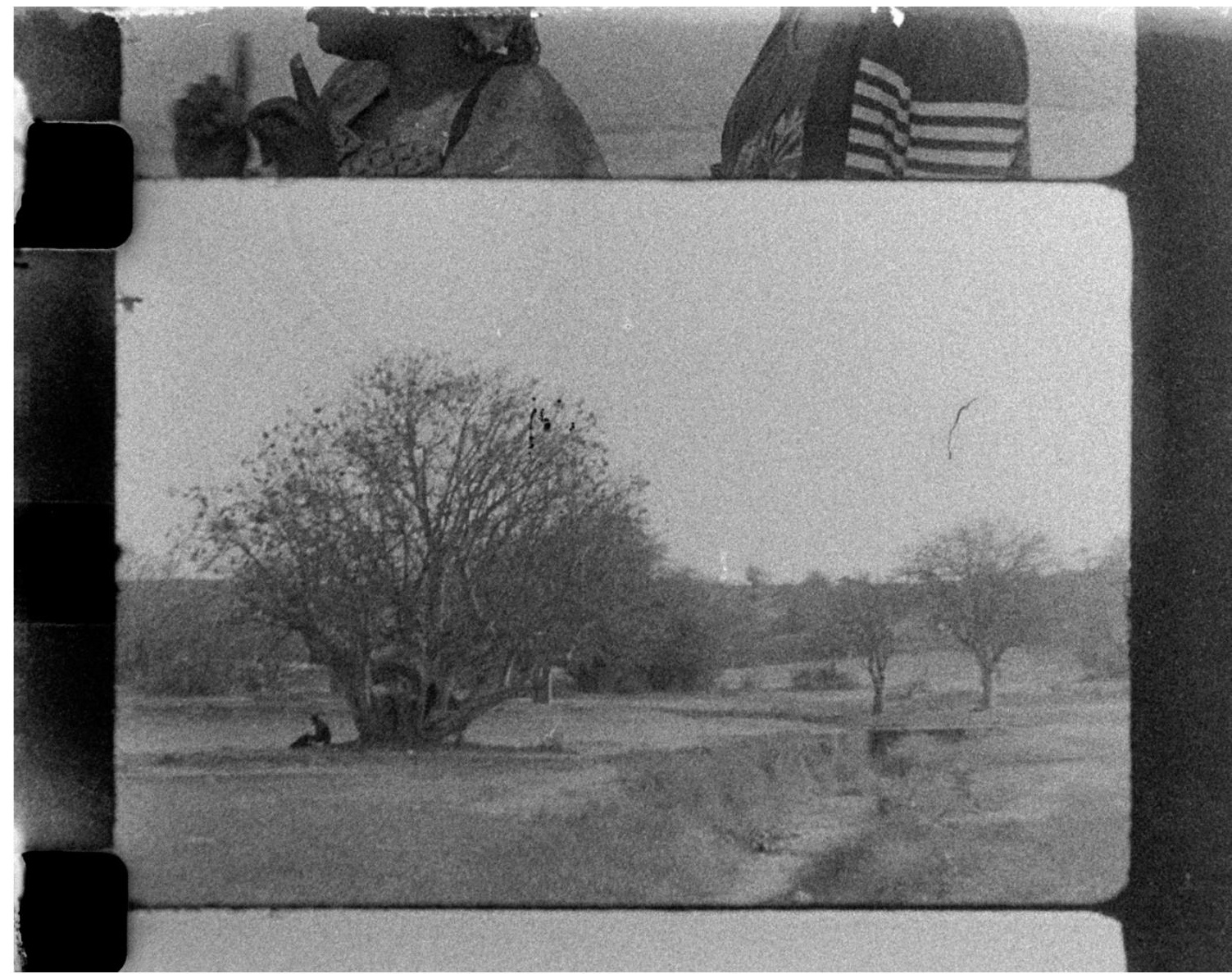

A relação descontínua entre o olhar e a visão ganhou na minha percepção tamanha intensidade que por vezes sentia-me paralisada diante do vazio, outras vezes percebia-me em pleno salto, experimentando um olhar surpreendente e inesperado, preenchido de visões. A compreensão da afirmação lacaniana de que o olhar passa pela visão chegou não sem angústias e medos. Como não poderia deixar de ser, ela trouxe consigo a percepção das lacunas, das faltas contingentes, tão desafiadoras em Luanda, e daquelas que são constitutivas do meu olhar, sempre submetido ao jogo entre a luz e aquilo que não consigo ver.

Assim que cheguei fui tomada pela sensação de que tudo o que via precisava ser filmado, no entanto, nada parecia mais difícil do que filmar em Luanda. Não eram apenas as dificuldades objetivas que me angustiavam e pareciam atrasar o andamento do trabalho, era preciso enfrentar o caráter evanescente e inapreensível de meu olhar, que parecia fragmentar minha própria relação com a luz. Como localizar o fenômeno a ser filmado nesse olhar que me cegava de luz, desde minha chegada nas outras margens do grande mar? 
Com o olhar preenchido pela visão dos olhos que me olham, tão continuamente a ponto de serem eles mesmos minha própria imagem, pesquisei a baixa de Luanda, as construções coloniais do centro da cidade. Buscando os sobrados coloniais me percebi olhada por suas ruínas, seus simulacros e pelos enormes arranha céus da cidade. Caminhar por Luanda em busca de um centro histórico é uma tarefa desoladora. Os antigos sobrados do século XVII e XVIII estão abandonados, muitos estão vazios e em estado de enorme precariedade, mantendo em pé apenas as grossas paredes da fachada. O largo do Pelourinho foi demolido e hoje é um estacionamento.

Enquanto caminhava pelo centro de Luanda, nas muitas vezes que andei em busca dos lugares de memória presentes na cidade, quase sempre me vinha a lembrança dos primeiros versos de um longo e emblemático poema de Derek Walcott, "O Mar é História".

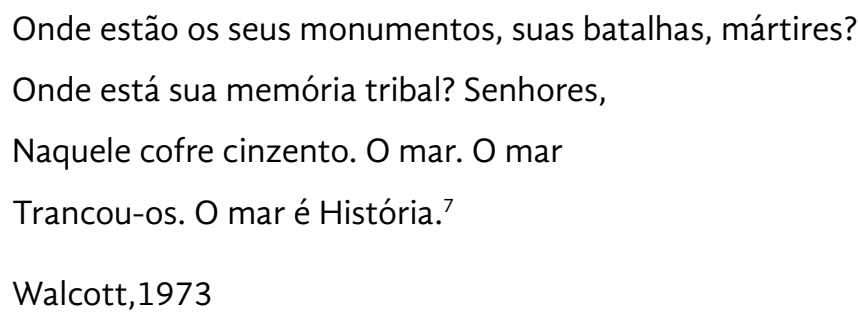

O poeta caribenho Derek Walcott foi presença importante em minhas leituras enquanto estive em Luanda. Seus versos foram ecoando em minha mente de forma cada vez mais intensa nos meses que passei na cidade e ao longo de todo o tempo que estive em Angola. A história é o mar? A perturbadora imagem central do poema de Walcott já estava presente no início de minha pesquisa, foi, no entanto, minha estadia em Angola quem trouxe a confirmação, da maneira a mais evidente, dessa sensação de naufrágio ao deparar-me com a história, a constatação da impossibilidade de conhece-la a partir dos seus monumentos e marcos oficiais.

Os centros históricos das cidades que viveram a colonização são museus a céu aberto da ocupação colonial. Em Luanda não é diferente. Mesmo es-

\footnotetext{
7 Where are your monuments, your battles, martyrs? Where is your tribal memory? Sirs, In that grey vault. The sea. The sea Has locked them up. The sea is History.

Walcott, Derek. The sea is history in: Derek Walcott Collected Poems 1948-1984. Nova York: Farrar, Straus \& Giroux, 1986. Ver ANEXO I com a tradução integral do poema.
} 
tando em explícito estado de abandono e alarmante precariedade, a baixa de Luanda contém traços valiosos das marcas da invasão colonial portuguesa, que evidenciam suas estratégias de ocupação e dominação. Sob a poeira das ruas e becos do centro de Luanda, muitas vezes irreconhecíveis pelo abandono a que estão submetidos, permanecem guardados importantes marcos não apenas do processo colonial, mas também da luta pela sua libertação.

Muito próximo a marginal está uma pequena praça arborizada com um curioso monumento que guarda um impressionante marco da independência de Angola. No centro da praça há um pedestal enorme, todo feito de pedra, com paredes muito largas onde está esculpido o brasão da coroa portuguesa. Sobre esse pedestal não existe nenhuma estátua, apenas grandes luminárias que apontam para baixo.

Pedestais sem estátuas são comuns no centro de Luanda. Eles são o resultado de uma prática realizada nos primeiros anos após a independência, quando as forças libertadoras comandadas pelo MPLA ${ }^{8}$ retiraram as estátuas dos portugueses que adornavam a cidade. Esses pedestais vazios de Luanda são um pulsante lugar de memória. Sendo o resultado de um processo de desconstrução violenta da estrutura colonial, eles exercem de forma contundente a crítica aos seus monumentos.

No pedestal vazio que encontrei nessa praça, algo chamou especialmente a minha atenção. Ao chegar perto do pedestal para observar atentamente o brasão, percebi que as figuras humanas esculpidas para adornar o brasão da coroa portuguesas estavam sem as suas cabeças. O trabalho das forças guerrilheiras vitoriosas ao ocupar a cidade após a libertação foi ideologicamente minucioso, além de retirar a estátua do colonizador, as pequenas figuras humanas que adornavam o brasão da coroa portuguesa também foram decapitadas.

Ao pesquisar a memória da cidade, investigo os monumentos urbanos enquanto arquivos coloniais. Interrogo a presença e a ausência da memória nos monumentos da cidade, a ideia e a imagem de passado que eles en-

8 MPLA é a sigla do "Movimento Popular pela Libertação de Angola", grupo guerrilheiro que liderou o movimento de libertação e se impôs como governo no momento da independência em 1975, travando uma longa guerra civil com as forças do grupo guerrilheiro UNITA. A guerra civil angolana termina com o assassinato do líder da UNITA Jonas Savimbi em 2002. 


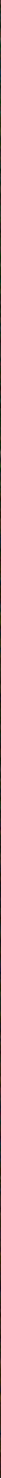

Figura 2

Cristiana Miranda

A Hidra do Iguaçu, 2020

. Fotograma do filme

carnam. Hal Foster fala do "impulso de arquivo", como algo que motiva o artista a tornar fisicamente presente a informação histórica que o paradigma colonial tenta excluir (Foster, 2004). Os monumentos urbanos podem ser pensados como espaços assombrados, habitados por fantasmas do passado. Trabalhar com os monumentos de forma crítica é um desejo não apenas de escavar suas histórias ocultas, mas também de exorcizar seus demônios.

Nos monumentos oficiais da cidade do Rio de Janeiro não existem traços que testemunham as lutas travadas pela nossa liberdade. Nossos monumentos são de um país que mantém um homem branco opressivamente em posição de comando sobre a população local. O monumento que glorifica a figura do opressor está intacto em nossas praças. Estará ele também intacto em nosso imaginário?

Quando realizei o filme "Sobre aquilo que nos diz respeito", o primeiro da série "Na risada salgada das rochas" meu desejo primordial foi cobrir as estátuas romanas do Jardim Suspenso do Valongo com mantos de palha. Com esse gesto o filme critica a presença de símbolos opressivos e coloniais nos 
espaços públicos do Rio de Janeiro. Foi preciso atravessar o oceano e viver em Luanda para compreender o incômodo que sinto ao caminhar por minha cidade. A violência da percepção dos estragos civilizatórios que a capital de Angola nos provoca traz consigo a possibilidade de perceber as lutas que fizeram parte da história desses estragos. As cabeças degoladas estão visíveis no monumento da cidade, mais do que visíveis, elas o marcam. $\mathrm{E}$ quando o monumento nos olha, não é uma única força opressiva que atua sobre nós, e sim os traços da guerra de forças presentes no conflito histórico de que o monumento é feito.

Figura 3

Cristiana Miranda Sobre aquilo que nos diz respeito, 2016 Fotograma do filme

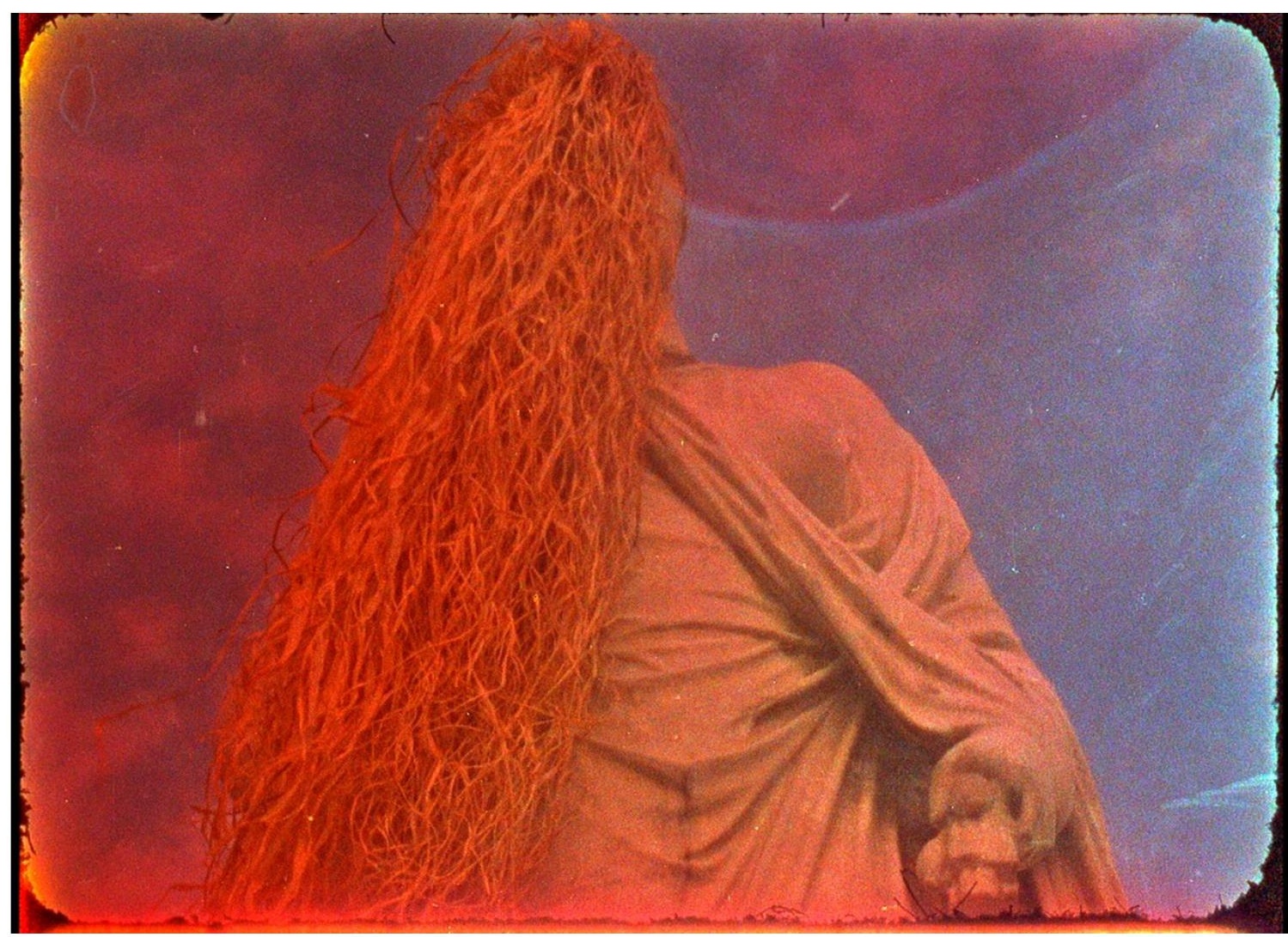

\section{A fúria das ondas}

A vida talvez seja uma experiência necessariamente violenta, nascer exige impetuosidade e fúria. Compreender o desfio que a violência da vida nos traz foi uma das necessidades de minha viagem. Angola despertou o apetite de meu olho, filmar foi um dos maiores desejos que experimentei desde que toquei com os pés as outras margens do Atlântico. Essa necessidade de alimentar meu olho com imagens trazia uma pesada bagagem. Para filmar era necessário não apenas encontrar o melhor enquadramento e a melhor hora da luz, era preciso também estabelecer uma estratégia para 
enfrentar a violência do olhar ao qual estava submetida. Se as imagens que ao fim consegui criar são belas, não saberia dizer, afirmo, no entanto, que elas são o registro de meu olho como desesperado pelo olhar.

Estar em um país estrangeiro é ter o outro diante dos olhos. É mesclar na experiência cotidiana das diferentes relações interpessoais a sensação de estar dentro e estar fora. Nessa mistura de pertencimentos e exclusões a face do outro nem sempre se impõe como uma exterioridade. Longas viagens nos fazem compreender que o fora não é o outro em nenhum sentido simples.

Minha viagem para Angola faz parte de uma pesquisa a cerca da memória e de seus lugares de encantamento. A noção de "lugares de memória" foi elaborada por Pierre Nora como uma ferramenta na construção de um método de investigação e inventário das memórias nacionais (Nora, 1984). Desse amplo e ambicioso projeto interessa-me a ideia de que existem alguns locais, sejam eles concretos ou não, onde a memória está incarnada, enraizada em suas fundações.

Os lugares de memória são objetos no abismo. Locais onde a imaginação e a construção simbólica trabalharam juntas para a construção de sinais de reconhecimento e pertencimento que se enraízam no concreto, no gesto, na imagem. Na noção de Nora, os "lugares" são compreendidos no sentido material, simbólico e funcional da palavra. A "memória" está voltada para a memória coletiva e se opõe ao termo história. A memória é trazida pelos grupos vivos e está sempre aberta à dialética da lembrança e do esquecimento, submetida a sucessivas deformações e vulnerabilidades, latências e revelações. A memória é sempre atual, um elo vivido no presente ${ }^{9}$.

Nos dois meses que fiquei em Luanda, antes de seguir para o sul de Angola, filmei e revelei os filmes preto e branco que havia trazido do Brasil. Para revelar as imagens em Luanda improvisei um laboratório na área externa do apartamento onde morava. Ali eu processava, lavava e secava o filme. Sempre pela manhã, o mais cedo possível, para aproveitar o silêncio e a tranquilidade da área externa que era compartilhada com outros moradores do mesmo andar no prédio. Para colocar o filme na espiral o melhor momento era à noite, o mais tarde possível, quando tudo estava tranquilo

9 Ver: Nora, Pierre. Les Lieux de Mémoire. Paris: Gallimard, 1984. 
e silencioso e eu podia me fechar no banheiro, o único local completamente escuro do apartamento.

Precisei de um termômetro e só encontrei termômetros eletrônicos, que não podem ser submersos na água. A temperatura adequada para o revelador usado para revelar a imagem preta e branca é 21 Graus Centígrados. Após muito procurar e não encontrar um termômetro para medir a temperatura do revelador, decidi resfriá-lo de maneira sensitiva deixando-o mais frio que a temperatura ambiente. O controle impreciso da temperatura da revelação não atrapalhou o resultado, com alívio e encantamento observei o contraste e a densidade das imagens ao pendurar o filme para secar no varal.

\section{Referências}

ALTUNA, Raul Ruiz de Asúa. Cultura Tradicional Bantu. Lisboa: 1985.

BENJAMIN, Walter. Textos escolhidos Sociologia. São Paulo: Editora Ática, 1985.

BRENEZ, Nicole. Cinémas d'avant garde. Paris: Cahiers du Cinémas, 2002.

FOSTER, Hal. O retorno do real. São Paulo: Cosac\&Naif, 2014.

FREUD, Sigmund. (1899) Lembranças Encobridoras. Edição Standard Brasileira das Obras Completas de Sigmund Freud, vol. III. Rio de Janeiro: Imago, 1996.

GEIMER, Peter. Inadvertent Images. Chicago: The University of Chicago Press, 2018.

GOMES, Flavio dos Santos. Para matar a Hidra uma história de quilombolas no recôncavo da Guanabara - Séc. XIX, Rio de Janeiro: Textos de História Revista da Pós-Graduação em História da UnB, v.2, n.3. 1994.

GURAN, Milton, ABREU Martha e MATTOS, Hebe. Inventário dos lugares de memória do tráfico atlântico dos africanos escravizados no Brasil. Niterói: PPGH-UFF, 2014.

KRENAK, Ailton. Ideias para adiar o fim do mundo. São Paulo: Companhia das letras, 2019.

LACAN, Jacques. O Seminário Livro 11: Os quatro conceitos fundamentais da psicanálise. Rio de Janeiro: Jorge Zahar Editor, 2008.

MBEMBE. Achille. Crítica da razão negra. São Paulo: n-1 edições, 2018. 
MURARI, Lucas e SOMBRA, Rodrigo. O cinema de John Akomfrah. Rio de Janeiro: Centro Cultural Banco do Brasil, 2018.

NORA, Pierre. Les Lieux de Mémoire. Paris: Gallimard. 1984.

RUFINO, Luiz e SIMAS, Luiz Antonio. Fogo no mato: a ciência encantada das macumbas. Rio de Janeiro: Mórula, 2018.

. Flecha no tempo. Rio de Janeiro: Mórula, 2019.

VIRILIO, Paul. Guérre et Cinéma l; Logique de la perception. Paris: Cahiers du Cinémas, 1991.

WALCOTT, Derek. The sea is history in: Derek Walcott Collected Poems 1948-1984. Nova York: Farrar, Straus \& Giroux, 1986.

WALL, Jeff. Essais et Entretiens 1984 - 2001. Paris: École National des Beaux Arts. 2001. 